\title{
Ultrafine titanium filaments with a high aspect ratio fabricated by the extraction from $\mathrm{Al}+\mathrm{Ti}$ composite
}

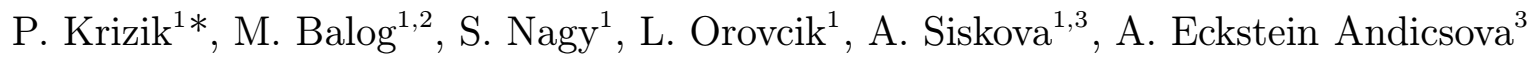 \\ ${ }^{1}$ Institute of Materials and Machine Mechanics, Slovak Academy of Sciences, \\ Dubravska cesta 9, 84513 Bratislava, Slovak Republic \\ ${ }^{2}$ Centre of Excellence for Advanced Materials Application, Slovak Academy of Sciences, \\ Dubravska cesta 9, 84511 Bratislava, Slovak Republic \\ ${ }^{3}$ Polymer Institute, Slovak Academy of Sciences, Dubravska cesta 9, 84541 Bratislava, Slovak Republic
}

Received 27 January 2020, received in revised form 18 May 2020, accepted 3 June 2020

\begin{abstract}
Titanium filaments were prepared by the extraction of powder metallurgy fabricated aluminum + titanium composite in sodium hydroxide solution. During the hot extrusion consolidation process, ultrafine aluminum powder particles heavily deformed the titanium powder particles into the titanium filaments of high aspect ratio and micrometric size, which were homogeneously embedded and arrayed in the aluminum matrix. The microstructure and chemistry of extracted titanium filaments were characterized in detail. For the demonstration purpose, the titanium filaments were sintered into a porous material.
\end{abstract}

K e y w or d s: aluminum (Al), titanium (Ti) filaments, composite material, extraction, powder metallurgy

\section{Introduction}

Titanium (Ti), known for its excellent chemical resistance and biocompatibility, has been widely applied in the chemical industry, military aircraft, and biomedicine [1]. A porous Ti structure is often utilized when an enhanced permeability or a decreased Young's modulus are of interest in the application such as corrosion-resistant filters, biomedical implants, spargers, heat exchangers, gas getters, catalyze supporters, sound and energy absorbers, electromagnetic shielding, etc. [2-4]. Various Ti pore structures, including uniform, bimodal, gradient, honeycomb-like, closed, etc. can be tailored according to the specific application $[5,6]$. Porous Ti materials have been fabricated using a variety of methods and approaches such as powder sintering, additive manufacturing, foaming, space holder technique, etc. [7]. Though, most of the manufacturing techniques still possess some limitations in terms of achieving fully opened porous structure, minimum pore size, density, and surface area of porous material [5]. One of the most promising groups of porous materials with high permeability and an active surface area are those produced from Ti fibers of micrometric size. However, owing to the limitation of the wire drawing technique, the minimum diameter of available Ti fiber is typically on the level of hundred micrometers [8]. According to the available information, the finest Ti fiber is produced by TOHO Titanium Co. LTD and has a diameter of $20 \mu \mathrm{m}$ and a length of $2.5 \mathrm{~mm}$ [9]. In order to enhance the properties of Ti porous materials, Ti fibers with the size on the level of micrometers are needed. However, they are not available, as an appropriate production technology is still missing at the moment. Titanium fibers of micrometric dimensions are highly required also for the preparation of various composite materials with a polymeric or metallic matrix. In the current work, a novel technology for the production of micrometric Ti filaments with high aspect ratio by the extraction of Ti from aluminum $(\mathrm{Al})+\mathrm{Ti}$ feedstock composite material is presented.

\section{Experimental}

Atomized $\mathrm{Al} 99.7 \mathrm{wt} . \%$ powder with the mean particle size $\left(d_{50}\right)$ of $1.15 \mu \mathrm{m}$ and hydro-dehydration

*Corresponding author: tel.: +421232401021; e-mail address: peter.krizik@savba.sk 

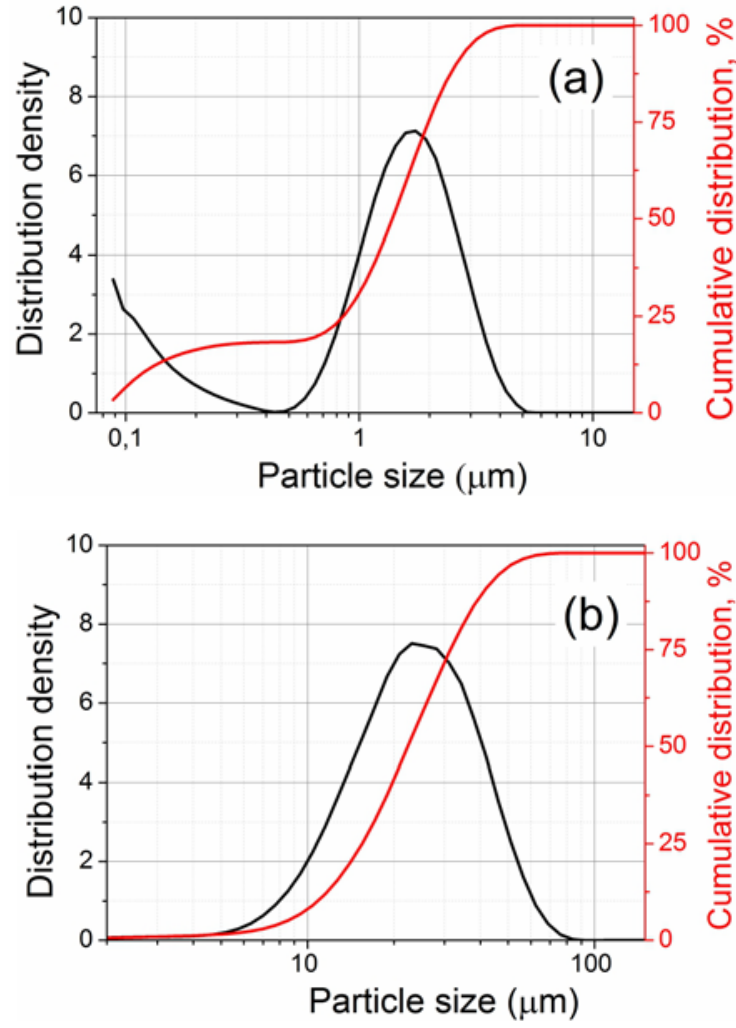

Fig. 1. The particle size distribution of used $\mathrm{Al}$ powder (a) and HDH Ti powder (b).

processed (HDH) Ti 99.4 wt.\% powder with $d_{50}=$ $24.5 \mu \mathrm{m}$ were used in this study. Particle size distribution (PSD) of used powders (Figs. 1a,b) was measured using Fritsch Analysette 22 MicroTec machine by wet dispersion in water. The chemical composition of $\mathrm{Al}$ powder is 0.044 wt.\% silicon $(\mathrm{Si}), 0.081 \mathrm{wt} . \%$ iron $(\mathrm{Fe})$, and bal. $\mathrm{Al}$, as was determined by Inductively Coupled Plasma Mass Spectrometry (ICP-MS, ICP 5500 Perkin-Elmer). The mixture of $\mathrm{Al}+18.52$ wt.\% Ti was homogenized in TURBULA shaker for $1 \mathrm{~h}$. The powder mixture was precompacted by cold isostatic pressing (CIP) at $150 \mathrm{MPa}$. CIP blank was extruded into $\mathrm{Al}+12$ vol.\% $\mathrm{Ti}$ composite rod with a diameter of $4.5 \mathrm{~mm}$ at the temperature of $425^{\circ} \mathrm{C}$ and using the reduction ratio of $31: 1$, representing the true strain of 3.43. Further details on the fabrication of $\mathrm{Al}+$ $\mathrm{Ti}$ composites can be found in our previous study [10]. In order to extract Ti filaments, the extruded $\mathrm{Al}+\mathrm{Ti}$ bar was dissolved in aqueous solution (10\%) of sodium hydroxide $(\mathrm{NaOH})$ with $98 \%$ purity. The filaments were purified by pure distilled water and isolated by centrifugation (Sigma 3-30K, Germany) with the rotation speed of $20000 \mathrm{rpm}$ for $10 \mathrm{~min}$ at $25^{\circ} \mathrm{C}$. Subsequently, the Ti filaments were dried at $45^{\circ} \mathrm{C}$ for $24 \mathrm{~h}$ in air. To demonstrate an application of Ti filaments as a filter, the dried filaments were cold pressed at $4 \mathrm{MPa}$, and then the disk with a diameter
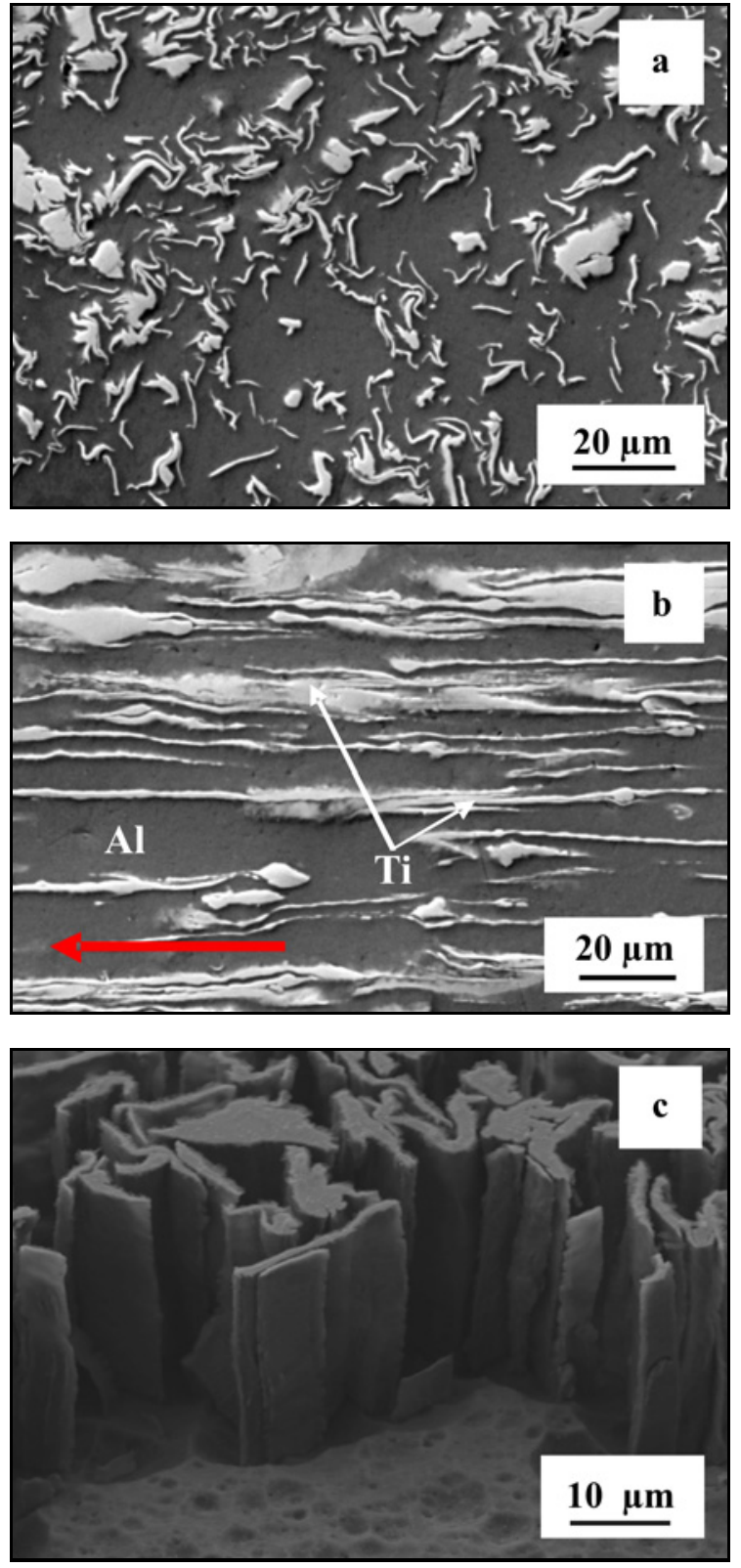

Fig. 2. SEM images of as-extruded $\mathrm{Al}+12$ vol. $\%$ Ti composite: (a) transversal, (b) longitudinal direction, and (c) deep-etched metallographic section showing the morphology of Ti filaments. (The red arrow shows the extrusion direction.)

of $5 \mathrm{~mm}$ and height of $2 \mathrm{~mm}$ was sintered at $1150^{\circ} \mathrm{C}$ for $2 \mathrm{~h}$ in argon. The microstructure of the $\mathrm{Al}+\mathrm{Ti}$ composite, the morphology of $\mathrm{Ti}$ powder, filaments and sintered material were characterized using scanning electron microscopy (SEM, JEOL 7500 machine) equipped with energy-dispersive X-ray spectroscopy (EDS). Interfaces between $\mathrm{Ti}$ filaments and $\mathrm{Al}$ matrix were characterized using scanning/transmission electron microscopy (STEM, FEI TITAN Themis machine) equipped with EDS. A specific surface area of 

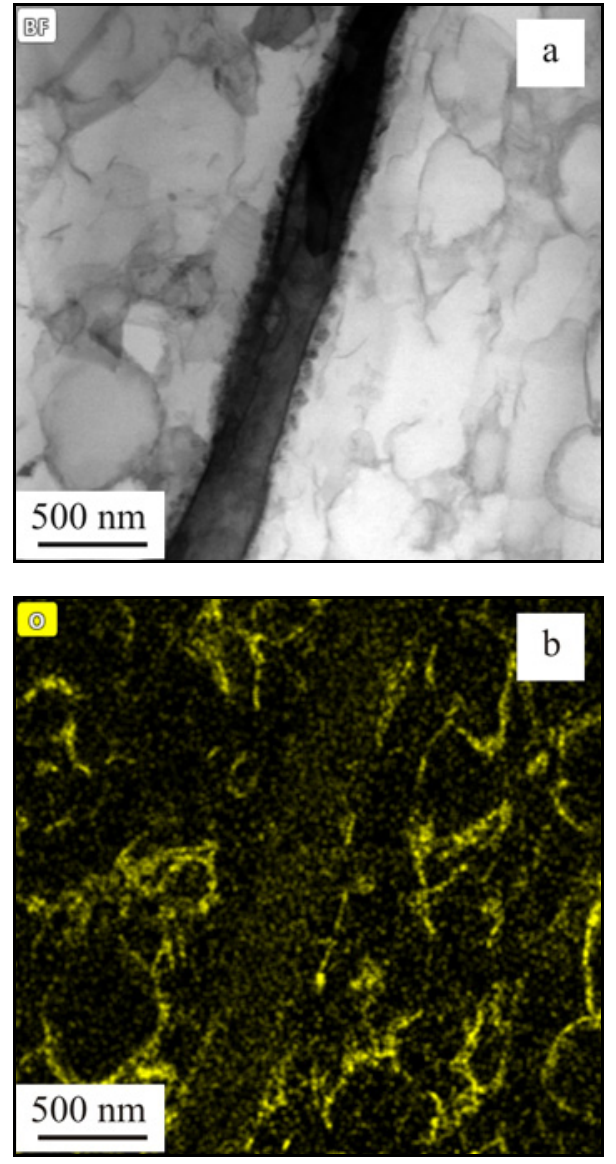

Fig. 3. Bright-field TEM image of $\mathrm{Al}+\mathrm{Ti}$ composite in transversal direction (a) with the corresponding oxygen EDS map (b).

Ti powder and filaments was determined by physical adsorption (BET principle). An average thickness of filaments was calculated according to the standard stereographic intercept method [11] using SEM. The length of extracted Ti filaments was determined using SEM and was averaged over 100 measurements of individual filaments.

\section{Results and discussion}

The representative longitudinal and transversal cross-sections of as-extruded $\mathrm{Al}+12$ vol.\% Ti composite are shown in Figs. 2a,b. High deformation resistance of fine $\mathrm{Al}$ powder experienced upon extrusion was comparable to the one of the coarse Ti powder. It resulted in severely textured Ti filaments elongated along the extrusion direction embedded in the $\mathrm{Al}$ matrix. High deformation resistance of $\mathrm{Al}$ powder is due to the fine $\mathrm{Al}$ grain size and stable nanometric network of amorphous $\mathrm{Al}_{2} \mathrm{O}_{3}$ formed at $\mathrm{Al}$ grain boundaries (Fig. 3), which stem from native passivation films on loose $\mathrm{Al}$ powder [12]. In spite of the relatively mod- erate true strain of 3.43 induced during hot extrusion compaction step, sub-micrometric Ti filaments with an average thickness of $0.66 \pm 0.14 \mu \mathrm{m}$ were formed. The Ti filaments exhibited a convoluted morphology as revealed by deep etching of the $\mathrm{Al}$ matrix in Fig. 2c. Considering the relatively low volume fraction of Ti filaments (12 vol.\%), the distribution of filaments in the $\mathrm{Al}$ matrix is homogeneous without a notable clustering. It is a typical microstructure observed for various deformation processed metal-metal composites in the as-deformed state $[13,14]$. A similar thickness of Ti filaments was also confirmed for other $\mathrm{Al}+\mathrm{Ti}$ composites [15]. It is anticipated that the size, morphology, and the aspect ratio of Ti filaments could be easily adjusted by the proper selection of $\mathrm{Al}$ and $\mathrm{Ti}$ powder sizes in combination with appropriate extrusion ratio and processing temperature.

A representative interface between the $\mathrm{Al}$ matrix and the Ti filament is shown in Figs. 4a,b,c. In spite of the low extrusion temperature used $\left(425^{\circ} \mathrm{C}\right)$, Al reacted with $\mathrm{Ti}$ during the extrusion process. For that reason, $\mathrm{Al}-\mathrm{Ti}$ interfaces were enriched for $\mathrm{Al}_{3} \mathrm{Ti}$ crystals with the size of tens of nm (Fig. 4d). Furthermore, the interface is enriched for $\mathrm{Si}$, which is present as an impurity in the metallic part of $\mathrm{Al}$ powder and diffuses towards the Ti component. Si layer, which forms between $\mathrm{Ti}$ filament and $\mathrm{Al}_{3} \mathrm{Ti}$ crystals, is amorphous with a thickness of $\sim 8 \mathrm{~nm}$ (Fig. $4 \mathrm{e}$ ). Owing to high deformation resistance of $\mathrm{Al}+\mathrm{Ti}$ powder mixture, it was technologically not feasible using a lower extrusion temperature than $425^{\circ} \mathrm{C}$, by which the formation of $\mathrm{Al}_{3} \mathrm{Ti}$ phase and the segregation of $\mathrm{Si}$ could be avoided or at least suppressed. The transversal crosssection of $\mathrm{Ti}$ filaments is composed of a few (2-3) $\mathrm{Ti}$ grains with a $\langle 10-10\rangle$ direction parallel to the extrusion direction (Fig. 4b), which is the typical texture for metals with a hexagonal close-packed structure.

Figures 5a,b compare the morphology of asreceived $\mathrm{HDH} \mathrm{Ti}$ powder and extracted Ti filaments. Even though some filaments fractured during the centrifugal separation, filaments with an average length of $177.3 \pm 78.5 \mu \mathrm{m}$ were obtained by the used extraction process. This fracturing is also due to the depletion of the plasticity of Ti filaments after the extrusion process.

According to the BET analysis results, Ti filaments showed a significant increase in the value of relative surface area from 0.15 to $29.3 \mathrm{~m}^{2} \mathrm{~g}^{-1}$ for the powder and filaments, respectively. In Fig. 6a the application of extracted Ti filaments for the fabrication of bulk porous material is demonstrated. A sound porous structure was obtained by the controlled sintering of Ti filaments, and at particular sintering conditions, the residual porosity of $42 \%$ obtained was determined.

As measured by EDS, the sintered Ti porous sample contains 2.73 wt. $\%$ Al, 1.2 wt. $\% \mathrm{Si}$, and bal. Ti. Owing to the solubility of $\mathrm{Si}$ in $\mathrm{Ti}(\sim 4$ at. $\% \mathrm{Si}$ at 

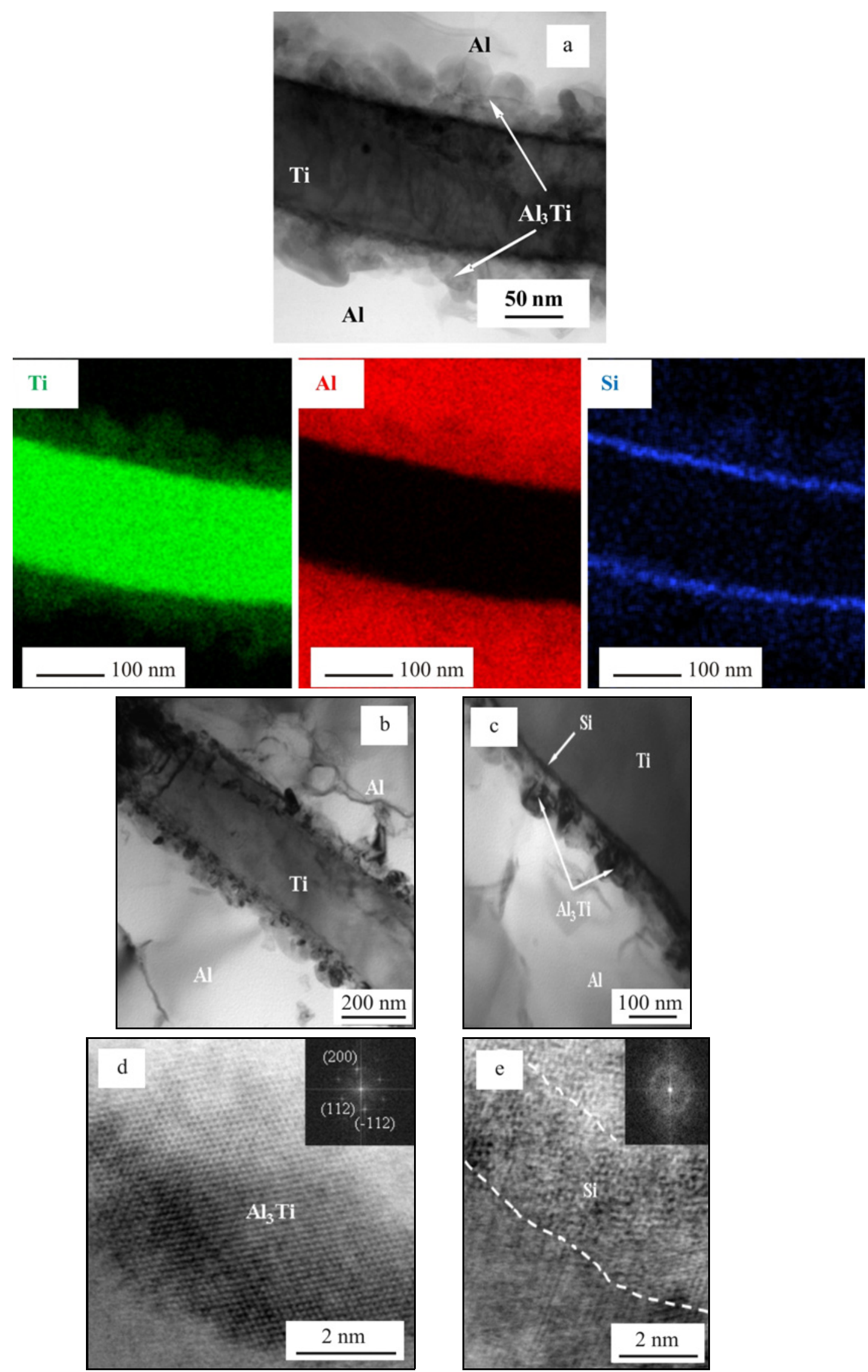

Fig. 4. (a) Bright-field STEM image of Al-Ti interface with the corresponding EDS maps of Ti, Al, and Si elements; (b, c) bright-field TEM images of Al-Ti interface; (d) bright-field HRSTEM image of $\mathrm{Al}_{3}$ Ti nanocrystal with the insert of Fast Fourier Transform (FFT) pattern of $\mathrm{Al}_{3} \mathrm{Ti}$; (e) bright-field HRTEM image of the amorphous Si layer with the insert of FFT pattern of Si. 

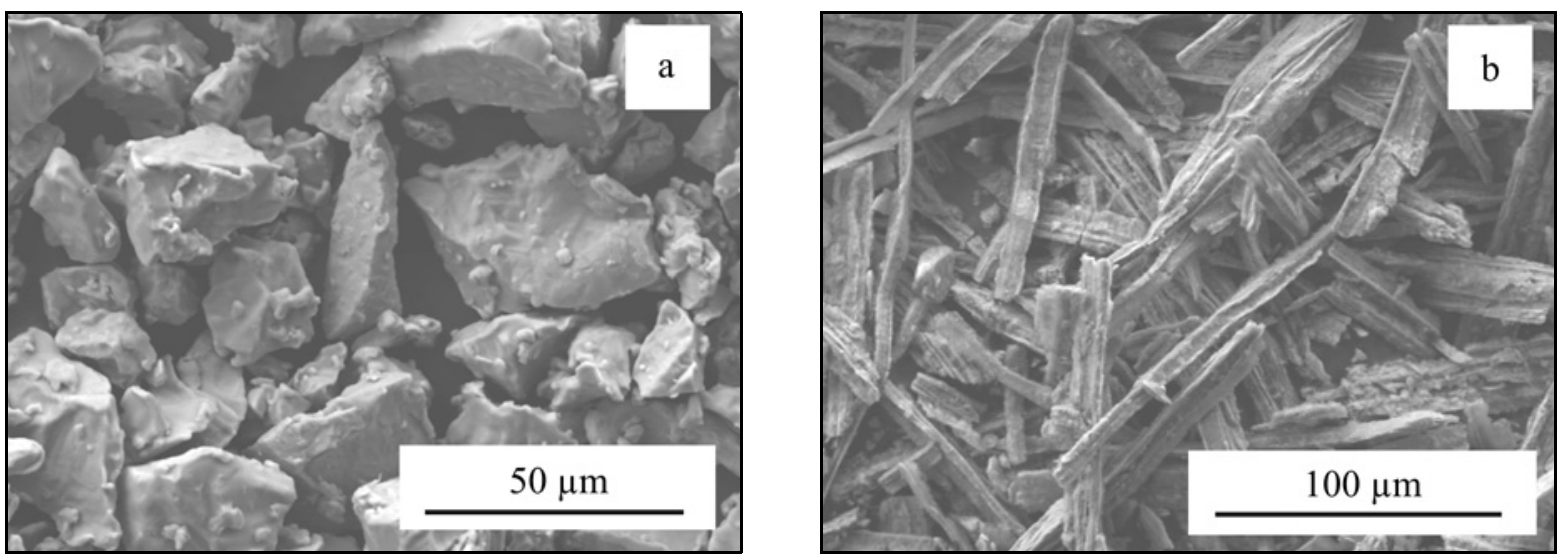

Fig. 5. SEM images of (a) Ti powder and (b) as-etched Ti filaments.
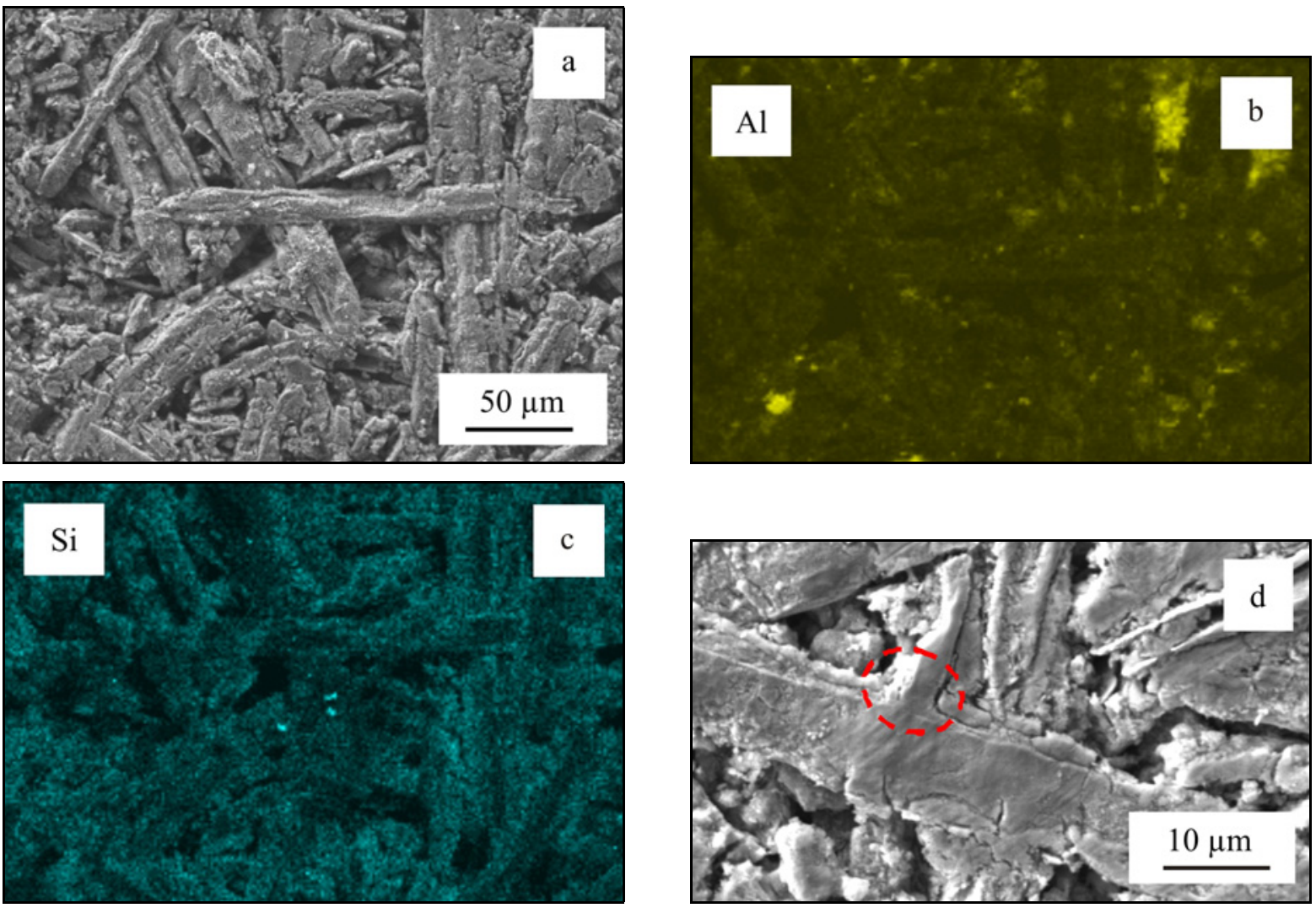

Fig. 6. SEM images of (a) the porous material sintered from Ti filaments with corresponding Al (b) and Si (c) EDS maps, and (d) the neck formed between Ti filaments during sintering (red dashed circle).

$\left.1150^{\circ} \mathrm{C}[16]\right)$, Si atoms were homogeneously dissolved in Ti during heating up to the sintering temperature, as shown in Si EDS map (Fig. 6a). Although some areas with higher $\mathrm{Al}$ content were occasionally observed (Figs. 6a-c), the dissolution of $\mathrm{Al}$ in sintered Ti filaments can be regarded as homogeneous. For this reason, we assume that either $\mathrm{Si}$ or $\mathrm{Al}$ does not significantly influence the sinterability of $\mathrm{Ti}$ filaments and the properties of porous Ti material. Figure $6 \mathrm{~d}$ shows a sintered neck formed between two adjacent Ti filaments evidencing good sinterability of extracted $\mathrm{Ti}$ filaments at the used technological condition.

\section{Conclusions}

Ti filaments with an average thickness of $0.66 \mu \mathrm{m}$ and with an average length of $177.3 \mu \mathrm{m}$ were successfully synthesized by the extraction from extruded powder metallurgical $\mathrm{Al}+\mathrm{Ti}$ composite in $\mathrm{NaOH}$ solution. The morphology, microstructure, and chemistry of extracted titanium filaments were investigated. The 
extracted Ti filaments had a high relative surface area of $29.3 \mathrm{~m}^{2} \mathrm{~g}^{-1}$. From extracted Ti filaments, a highly permeable material with resulting porosity of $42 \%$ was prepared by the sintering.

\section{Acknowledgements}

This work was supported by the Slovak Scientific Agency under the APVV-16-0527 project, VEGA 2/0143/ 20 project, and VEGA $2 / 0114 / 18$ project. The authors thank Mrs. V. Trembosova for help with SEM characterization. This work was performed during the implementation of the project Building-up Centre for Advanced Materials Application of the Slovak Academy of Sciences, ITMS project code 313021 T081 supported by Research \& Innovation Operational Programme funded by the ERDF.

\section{References}

[1] C. Leyens, M. Peters (Eds.), Titanium and Titanium Alloys: Fundamentals and Applications, first ed., Wiley-VCH Verlag GmbH \& Co. KGaA, Weinheim, 2003. ISBN: 9783527305346.

[2] B. V. Krishna, S. Bose, A. Bandyopadhyay, Low stiffness porous Ti structures for load bearing implants, Acta Biomater. 3 (2007) 997-1006. doi:10.1016/j.actbio.2007.03.008

[3] Homepage GNK Powder Metallurgy, https://www.gknpm.com/en/our-businesses/ gkn-sinter-metals/porous-metal-filters/, (accessed on January $\left.20^{\text {th }}, 2020\right)$.

[4] S. F. Liu, A. Li, Y. J. Ren, D. F. Li, Z. H. Zhang, Heat transfer performance of porous titanium, J. Iron \& Steel Res. Int. 24 (2017) 556-560. doi:10.1016/S1006-706X(17)30083-3

[5] H. P. Tang, J. Wang, M. Qian, Porous titanium structures and applications. in: M. Qian and F. H. Froes (Eds.), Titanium Powder Metallurgy, Science, Technology and Applications, Butterworth-Heinemann, 2015 , pp. $533-554$. doi:10.1016/B978-0-12-800054-0.00028-9
[6] Z. P. Xi, J. L. Zhu, H. P. Tang, Q. B. Ao, H. Zhi, J. Y. Wang, C. Li, Progress of application researches of porous fiber metals, Materials 4 (2011) 816-824. doi: $10.3390 / \operatorname{ma} 4040816$

[7] B. Xie, Y. Z. Fan, T. Z. Mu, B. Deng, Fabrication and energy absorption properties of titanium foam with $\mathrm{CaCl}_{2}$ as a space holder, Mater. Sci. Eng. A 708 (2017) 419-423. doi:10.1016/j.msea.2017.09.123

[8] S. F. Liu, Z. P. Xi, H. P. Tang, X. Yang, Z. H. Zhang, Compressive behavior of porous titanium fiber materials, J. Iron \& Steel Res. Int. 21 (2014) 793-796. doi:10.1016/S1006-706X(14)60143-6

[9] Homepage TOHO TITANIUM CO. LTD., https://www.toho-titanium.co.jp/en/products/ webtihp.html, (accessed on January 20 $0^{\text {th }}, 2020$ ).

[10] P. Krizik, M. Balog, M. Nosko, M. V. C. Riglos, J. Dvorak, O. Bajana, Ultrafine-grained $\mathrm{Al}$ composites reinforced with in-situ $\mathrm{Al}_{3} \mathrm{Ti}$ filaments, Mater. Sci. Eng. A 657 (2016) 6-14. doi:10.1016/j.msea.2016.01.047

[11] E. E. Underwood, Quantitative Stereology, first ed., Addison-Wesley, Kittery, 1970. ISBN-10: 0201076500.

[12] M. Balog, T. Hu, P. Krizik, M. V. C. Riglos, B. D. Saller, H. Yang, J. M. Schoenung, E. J. Lavernia, On the thermal stability of ultrafine-grained Al stabilized by in-situ amorphous $\mathrm{Al}_{2} \mathrm{O}_{3}$ network, Mater. Sci. Eng. A 648 (2015) 61-71. doi:10.1016/j.msea.2015.09.037

[13] G. X. Wang, M. Dahms, G. Leitner, S. Schultrich, Titanium aluminides from cold-extruded elemental powders with Al-contents of 25-75 at.\% Al, J. Mater. Sci. 29 (1994) 1847-1853. doi:10.1007/BF00351304

[14] P. B. Wheelock, K. Wongpreedee, A. M. Russell, L. S. Chumbley, A deformation processed $\beta$ - Ti $+\mathrm{Y}$ metal-metal composite, J. Mater. Sci. 37 (2002) 4307-4313. doi:10.1023/A:1020644317324

[15] A. M. Russell, T. Lund, L. S. Chumbley, F. A. Laabs, L. L. Keehner, J. L. Harringa, A high-strength, high-conductivity Al-Ti deformation processed metalmetal matrix composite, Composites: Part A 30 (1999) 239-247. doi:10.1016/S1359-835X(98)00163-8

[16] H. Okamoto, Phase Diagrams for Binary Alloys, second ed., ASM International, Ohio, 2010. ISBN-13: 9781-61503-046-0. 